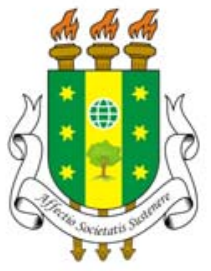

ZRBADM

Journal homepage:

www.arvore.org.br/seer

\section{CIDADES DIGITAIS E GOVERNO ELETRÔNICO: INOVAÇÃO PARA QUAL CIDADANIA?}

\section{RESUMO}

O recente e rápido desenvolvimento das TICs - Tecnologias de Informação e Comunicação provocou profundas alterações nas relações comerciais, sociais e políticas, impactando a soberania do Estado. Uma das aplicações das tecnologias de informação é o desenvolvimento de um modelo de governança (governance) que se instituiu e toma forma por meio do governo eletrônico (e-gov) e da prestação de serviços em rede visando em última instância a busca pela democracia digital. No contexto descrito nesse trabalho pretendeu-se iniciar um estudo sobre a influência da participação digital num clássico problema de filosofia política, a cidadania. O trabalho, a partir de uma revisão teórica sobre os tópicos relacionados e dados empíricos de pesquisa governamental, teve como objetivo analisar a importância da difusão da inovação no projeto das Cidades Digitais, como forma efetiva da utilização dos serviços de governo eletrônico, ampliação da participação cidadã e o consequente exercício da cidadania digital. Um debate que traz à discussão a importância do processo de difusão da inovação como catalizador da real utilização desse projeto. A implantação do efetivo governo eletrônico enfrenta desafios de várias ordens, entre eles as questões organizacionais, jurídicas e principalmente, culturais, presentes e divergentes em cada cidade digital que precisam ser trabalhados num correto processo de difusão da inovação para que de fato venha a possibilitar a participação digital e, para que possa gerar como consequência desse projeto das Cidades Digitais: a utilização de uma inovação como caminho para a prática da cidadania digital.

PALAVRAS-CHAVES: Cidades Digitais; Governo Eletrônico; Cidadania Digital.

\section{E-GOVERNMENT AND DIGITAL CITIES: INNOVATION FOR WHICH CITIZENSHIP?}

\section{ABSTRACT}

The recent rapid development of ICT - Information and Communication Technologies provoked profound changes in trade, social and political relations, impacting state sovereignty. One of the applications of information technologies is the development of a model of governance (governance) that was instituted and takes form through the electronic government (e-gov) and the provision of network services in order ultimately to search for digital democracy. In the context described in this work intended to initiate a study on the influence of digital participation in a classic problem of political philosophy, citizenship. The work, from a theoretical review of related topics and empirical research government, aimed to analyze the importance of diffusion of innovation in the design of Digital Cities as an effective use of e-government services, widening participation citizen and the resulting digital citizenship. A debate that brings to the discussion the importance of the process of diffusion of innovation as a catalyst for real use in this project. The implementation of effective e-government faces challenges of various orders, including the organizational, legal, and especially cultural, gifts and divergent in each digital city that need to be worked out in a correct process of diffusion of innovation that actually will allow participation and digital, so you can generate as a result of this project digital Cities: the use of an innovation as a way to practice digital citizenship.

KEYWORDS: Digital Cities; Electronic Government; Digital Citizenship.
Revista Brasileira de Administração Científica, Aquidabã, v.4, n.2, Ago 2013.

\section{ISSN 2179-684X}

\section{SECTION: Articles}

TOPIC: Sistemas e Tecnologia da Informação

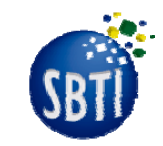

Anais do Simpósio Brasileiro de Tecnologia da Informação (SBTI 2013)

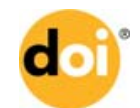

DOI: 10.6008/ESS2179-684X.2013.002.0006

\section{Maria Ângela da Costa Lino Franco Sampaio \\ Universidade Federal da Bahia, Brasil http://lattes.cnpq.br/2158578076593165 angelacostalino@gmail.com}

\section{Milton Correia Sampaio Filho}

Universidade Salvador, Brasil http://lattes.cnpq.br/9390350799676232 miltonsampaiofilho@gmail.com

\section{Ernani Marques dos Santos}

Universidade Federal da Bahia, Brasil http://lattes.cnpq.br/5388965130432483 emarques@ufba.br

Received: 07/07/2013

Approved: 05/08/2013

Reviewed anonymously in the process of blind peer.

\section{Referencing this:}

SAMPAIO, M. A. C. L. F.; SAMPAIO FILHO, M. C.; SANTOS,

E. M.. Cidades digitais e governo eletrônico: inovação para qual cidadania?. Revista Brasileira de

Administração Científica, Aquidabã, v.4, n.2, p.81-95, 2013. DOI: $\underline{\text { http://dx.doi.org/10.6008/ESS2179- }}$ $\underline{684 X .2013 .002 .0006}$ 


\section{INTRODUÇÃO}

O recente e rápido desenvolvimento das TICs - Tecnologias de Informação e Comunicação provocou profundas alterações nas relações comerciais, sociais e políticas, alterando conforme Castells (2003) a soberania do Estado. Uma das aplicações das tecnologias de informação é o desenvolvimento de um modelo de governança (governance) que se instituiu e toma forma por meio do governo eletrônico (e-gov) e da prestação de serviços em rede.

Esperava-se que a Internet fosse um instrumento ideal para promover a democracia - e ainda se espera. Como dá fácil acesso a informação política, permite aos cidadãos ser quase tão bem informados quanto os seus líderes. Com boa vontade do governo, todos os registros públicos, bem como um amplo espectro de informação não sigilosa, poderia ser disponibilizado on-line. A interatividade torna possível aos cidadãos solicitar informações, expressar opiniões e pedir respostas pessoais a seus representantes. (CASTELLS, 2003, p.128).

De acordo com Jardim (2007), o aparelho de Estado faz uso das novas tecnologias para oferecer à sociedade melhores condições de acesso à informação e serviços governamentais, ampliando a qualidade desses serviços e garantindo maiores oportunidades de participação social no processo democrático. Segundo as diretrizes do Comitê Executivo do Governo Eletrônico CEGE (2010), a prioridade do Governo Eletrônico é a promoção da cidadania, sendo a Inclusão Digital indissociável do Governo Eletrônico; como aborda Mimicopoulos et al. (2007), para os quais a era da informação tem alterado o conceito de governança, já que as TICs podem ser utilizadas para facilitar as operações do governo, bem como envolver a sociedade civil proporcionando melhor transparência, eficiência e maior qualidade nos serviços. Para implantar essa política, Santos (2008a, 2008b) considera que a implementação do governo eletrônico passa por uma evolução em três etapas: presença na internet através de informações básicas, capacidades de transação para indivíduos e empresas e informações e transações integradas com a colaboração de diversas agências. Mas, para ele, a transição para o último estágio envolve desafios políticos, estratégicos e de cooperação entre os envolvidos para efetivamente abrigar a participação cidadã.

Buscando esse objetivo da inclusão digital e consequentemente da utilização de todo o potencial do projeto de Governo Eletrônico, o governo federal criou um projeto de inovação para transformar determinadas cidades que possuíam maior dificuldade de acesso às TICs e a processos de governo eletrônico em Cidades Digitais. Para Lemos (2006), nessa reorganização das cidades existentes, nessa nova relação entre o espaço urbano (e suas práticas) e as tecnologias digitais de informação e comunicação e o governo, há, ao menos no discurso, a promoção de um vínculo social, a inclusão digital, democratização do acesso à informação, permitindo melhor e maior exercício da política pelo indivíduo-cidadão digital, ou o cibercidadão.

As inovações, no entanto, para serem socializadas, precisam da difusão, que assume características específicas que, corretamente trabalhadas, podem auxiliar nos objetivos de organizações inovadoras, quer sejam governos, empresas ou entidades que produzem ciência e tecnologia. (GIACOMINI et al., 2007, p. 41) 
Para Rodriguez (2007), a experiência mostra que os projetos e as políticas públicas tornam-se mais efetivos quando apenas conduzem os processos de difusão de inovações, em vez de pura e simplesmente executá-los. Ou, em outras palavras, quando constroem as condições, junto à sociedade civil, para que o processo de desenvolvimento tecnológico desejado seja deslanchado.

Esse trabalho procura analisar a importância da difusão da inovação no projeto de Cidades Digitais como forma efetiva da utilização dos serviços de governo eletrônico, ampliação da participação cidadã e o consequente exercício da cidadania digital.

\section{METODOLOGIA}

O presente trabalho apresenta-se como um ensaio teórico, resultado da análise de pesquisas descritivas, mais para levantar questões problematizadoras que encontrar respostas, mais como estruturante de diretrizes de novas pesquisas e ações que poderão culminar na ampliação de estudos sobre a relação entre o projeto de inovação das Cidades Digitais e os processos de Governo Eletrônico na construção da Cidadania Digital no Brasil.

\section{DISCUSSÕES TEÓRICAS}

\section{Cidades Digitais e Governo Eletrônico}

O tema governo eletrônico ingressou nas agendas governamentais, como assunto de grande relevância, notadamente associado aos movimentos de reforma do Estado, configurandose como um dos instrumentos para a modernização da gestão pública e para dotar o governo de mais eficiência. O entendimento de governo eletrônico, segundo Fernandes (2006), surge inicialmente para designar o processo de transformações nas estruturas e relações internas e externas dos vários níveis do Estado e da Administração Pública através da incorporação e da potencialização das TICs, quer no plano das relações internas (G2G - Government to Government), quer no das relações externas (G2B e G2C - Government to Business e Government to Citizens), oferecendo serviços públicos mais eficientes e orientados ao cidadão, serviços de qualidade de modo a facilitar o acesso aos processos de governo e encorajar a participação do cidadão.

Segundo Azizan et al. (2011) as tecnologias e técnicas de governo eletrônico são utilizadas no mundo contemporâneo, principalmente via websites para estabelecer relacionamento, prover recursos de conhecimento (informação e serviços) aos usuários (stakeholders), particularmente cidadãos, empresas e outros órgãos governamentais, atendendo, segundo Sagheb-Tehrani (2010), tanto as necessidades dos usuários internos como externos, através de tecnologias efetivas, serviços de entrega eficiente e engajamento tanto da administração pública quanto da 
comunidade, permitindo a criação de ambientes com alto grau de accountability e participação na elaboração e condução das políticas públicas.

O projeto das Cidades Digitais foi elaborado a partir da análise de pesquisas realizadas que demonstraram a inexistência ou dificuldades de acesso às TICs em determinadas regiões e camadas da população. Com base em pesquisas realizadas pelo NIC - Núcleo de Informação e Coordenação do Ponto BR (2012) do CGI - Comitê Gestor da Internet no Brasil, pode-se observar na tabela 1 que 55\% dos domicílios pesquisados ainda não dispõem de computador, principalmente nas famílias com renda inferior a três salários mínimos (90\%), sendo esse percentual extremamente elevado, independente da renda, na área rural (84\%) e em termos de região, nas regiões norte (68\%) e nordeste (75\%).

Tabela 1: Percentual de Domicílios com Computador

\begin{tabular}{l|l|l|l|l}
\hline \multicolumn{2}{l}{ Percentual (\%) } & Sim & Não & Não sabe / Não respondeu \\
\hline \multicolumn{1}{l|}{ Total } & Urbana & 45 & 55 & 0 \\
\cline { 2 - 5 } & Rural & 51 & 49 & 0 \\
& Sudeste & 16 & 84 & 0 \\
\cline { 2 - 5 } & Nordeste & 57 & 43 & 0 \\
\cline { 2 - 5 } & Sul & 25 & 75 & 0 \\
\cline { 2 - 5 } & Norte & 56 & 44 & 0 \\
\cline { 2 - 5 } & Centro-Oeste & 32 & 68 & 0 \\
\hline \multirow{5}{*}{ Renda familiar } & Até 1 SM & 47 & 53 & 0 \\
\cline { 2 - 5 } & Mais de 1 SM até 3 SM & 10 & 90 & 0 \\
\cline { 2 - 5 } & Mais de 3 SM & 38 & 62 & 0 \\
\hline
\end{tabular}

Nota. Base: 25000 domicílios. Fonte: Adaptado pela autora a partir de dados do Núcleo de Informação e Coordenação do Ponto BR (2012). Pesquisa sobre o uso das tecnologias de informação e comunicação no Brasil: TIC Domicílios e TIC Empresas 2011. (p. 435). SP: CGI.

A pesquisa demonstrou também que em relação aos domicílios que possuem computador, ainda há um grande problema de acesso à internet. A tabela 2 mostra que 62\% dos domicílios não têm acesso a internet e esse número é ainda mais elevado nas camadas de renda inferior até três salários mínimos (94\%), nas regiões norte (78\%) e nordeste (79\%) e principalmente na área rural (90\%).

Tabela 2: Percentual de Domicílios com Acesso a Internet

\begin{tabular}{|c|c|c|c|c|}
\hline \multicolumn{2}{|c|}{ Percentual (\%) } & Sim & Não & Não sabe I Não respondeu \\
\hline \multicolumn{2}{|c|}{ Total } & 38 & 62 & 0 \\
\hline \multirow{2}{*}{ Área } & Urbana & 43 & 57 & 0 \\
\hline & Rural & 10 & 90 & 0 \\
\hline \multirow{5}{*}{ Região } & Sudeste & 49 & 51 & 0 \\
\hline & Nordeste & 21 & 79 & 0 \\
\hline & Sul & 45 & 55 & 0 \\
\hline & Norte & 22 & 78 & 0 \\
\hline & Centro-Oeste & 39 & 61 & 0 \\
\hline \multirow{3}{*}{$\begin{array}{l}\text { Renda } \\
\text { familiar }\end{array}$} & Até $1 \mathrm{SM}$ & 6 & 94 & 0 \\
\hline & Mais de $1 \mathrm{SM}$ até $3 \mathrm{SM}$ & 29 & 71 & 0 \\
\hline & Mais de $3 \mathrm{SM}$ & 75 & 25 & 0 \\
\hline
\end{tabular}

Nota. Base: 25000 domicílios. Fonte: Adaptado pela autora a partir de dados do Núcleo de Informação e Coordenação do Ponto BR (2012). Pesquisa sobre o uso das tecnologias de informação e comunicação no Brasil: TIC Domicílios e TIC Empresas 2011. (p. 438). SP: CGI.

Mesmo para aqueles que são usuários da internet, pode-se verificar a partir da Tabela 3, que $26 \%$ desses usuários utilizam a internet fora da sua residência sendo que $14 \%$ desses usuários pagam pelo serviço. Esse número de usuários que pagam pelo serviço cresce ainda 
nas regiões norte $(27 \%)$ e nordeste (25\%) e nas camadas de menor renda da população, até três salários mínimos, com um percentual de $39 \%$.

Tabela 3: Local de Acesso mais frequente e Internet

\begin{tabular}{|c|c|c|c|c|}
\hline \multicolumn{2}{|c|}{ Percentual (\%) } & Em casa & Centro público de acesso pago & No trabalho \\
\hline \multicolumn{2}{|c|}{ Total } & 59 & 14 & 12 \\
\hline \multirow{2}{*}{ Área } & Urbana & 61 & 14 & 13 \\
\hline & Rural & 38 & 27 & 10 \\
\hline \multirow{5}{*}{ Região } & Sudeste & 65 & 10 & 13 \\
\hline & Nordeste & 48 & 25 & 9 \\
\hline & Sul & 63 & 8 & 16 \\
\hline & Norte & 43 & 27 & 13 \\
\hline & Centro-Oeste & 56 & 19 & 13 \\
\hline \multirow{3}{*}{$\begin{array}{l}\text { Renda } \\
\text { familiar }\end{array}$} & Até $1 \mathrm{SM}$ & 26 & 39 & 4 \\
\hline & Mais de 1 SM até 3 SM & 52 & 19 & 29 \\
\hline & Mais de $3 \mathrm{SM}$ & 70 & 6 & 24 \\
\hline
\end{tabular}

Nota. Base: 11336 pessoas que usaram a Internet há menos de três meses em relação ao momento da entrevista. Fonte: Adaptado pela autora a partir de dados do Núcleo de Informação e Coordenação do Ponto BR (2012). Pesquisa sobre o uso das tecnologias de informação e comunicação no Brasil: TIC Domicílios e TIC Empresas 2011. (p. 454). SP: CGI.

As políticas de governo eletrônico (e-gov) foram elaboradas como instrumentos essenciais para a prestação de serviços públicos, assim como para a extensão dos mecanismos de participação e responsividade da administração pública, entretanto há resistência à utilização desses canais pela maior parte da população. De acordo com a pesquisa realizada pelo NIC (2012) das 6680 pessoas pesquisadas, 69\% das pessoas não utilizaram serviços de governo eletrônico no período de um ano. Essa resistência encontra fundamento baseado na cultura local onde do total de pessoas que não utilizaram esses serviços, conforme tabela 4 a seguir, 69\% informou que prefere o contato pessoal demonstrando a crença de que apenas consegue solução caso haja o contato pessoal. Além disso, outros motivos interessantes apareceram como a questão da utilização da tecnologia, já que 11\% considera que utilizar a internet para contato com a administração pública é muito complicado, o que demonstra que não só a disponibilização do serviço é garantia de utilização. Por último, a pesquisa aponta que nem sempre o retorno é efetivo, já que 4\% dos entrevistados afirmam não receber o retorno às suas solicitações, sendo esse percentual ampliado na região norte (9\%) e para a camada com renda acima de três salários mínimos (6\%) e que consequentemente tem um nível de exigência maior, o que, como causa, já envolve a questão dos processos de governo eletrônico, sua eficiência e credibilidade.

Tabela 4: Motivos para não exercer a e-participação no governo eletrônico

\begin{tabular}{|c|c|c|c|c|}
\hline \multicolumn{2}{|c|}{ Percentual (\%) } & $\begin{array}{l}\text { Prefiro fazer } 0 \\
\text { contato } \\
\text { pessoalmente }\end{array}$ & $\begin{array}{l}\text { Usar a Internet para contato com } \\
\text { a administração pública é muito } \\
\text { complicado }\end{array}$ & $\begin{array}{l}\text { Dificilmente recebo } \\
\text { retorno (resposta) às } \\
\text { minhas solicitações }\end{array}$ \\
\hline \multicolumn{2}{|l|}{ Total } & 69 & 11 & 4 \\
\hline \multirow{2}{*}{ Área } & Urbana & 69 & 11 & 4 \\
\hline & Rural & 68 & 10 & 4 \\
\hline \multirow{5}{*}{ Região } & Sudeste & 67 & 10 & 3 \\
\hline & Nordeste & 72 & 14 & 4 \\
\hline & Sul & 73 & 8 & 6 \\
\hline & Norte & 64 & 7 & 9 \\
\hline & $\begin{array}{l}\text { Centro- } \\
\text { Oeste }\end{array}$ & 63 & 11 & 4 \\
\hline Renda & Até $1 \mathrm{SM}$ & 68 & 13 & 8 \\
\hline
\end{tabular}




\begin{tabular}{l|l|l|l|l|}
\hline familiar & $\begin{array}{l}\text { Mais de 1 } \\
\text { SM até 3 SM }\end{array}$ & 73 & 10 & 4 \\
\cline { 2 - 6 } & $\begin{array}{l}\text { Mais de 3 } \\
\text { SM }\end{array}$ & 11 & 6 & \\
\hline
\end{tabular}

Nota. Base: 4143 pessoas que não utilizaram serviços de governo eletrônico nos últimos 12 meses em relação ao momento da entrevista, mas utilizaram a Internet. Fonte: Adaptado pela autora a partir de dados do Núcleo de Informação e Coordenação do Ponto BR (2012). Pesquisa sobre o uso das tecnologias de informação e comunicação no Brasil: TIC Domicílios e TIC Empresas 2011. (p. 485-4878). SP: CGI.

Anjos e Ezequiel (2011) argumentam que, não só há pouca utilização desses canais devido a dificuldade de acesso da população pelos dados expostos anteriormente, bem como mesmo tendo sido concebido para ser um novo e eficiente canal de comunicação entre Estado e cidadãos, o e-gov ainda funciona (muitos anos depois de implantado) muito mais como um quadro de avisos eletrônico, no qual as informações julgadas importantes por quem as publica são disponibilizadas e com pouquíssima possibilidade de interação, do que efetivamente um canal adicional expressivo de comunicação entre a administração pública e seus usuários, como pode ser observado nos dados da tabela 5 abaixo, que demonstram que apenas $10 \%$ dos usuários de governo eletrônico participam em foruns, chats e votações relacionados aos assuntos de governo, ou seja a e-participação é praticamente nula e ainda mais quando se observa os valores da área rural (8\%) e das camadas menos favorecidas da sociedade com renda de até três salários mínimos (6\%).

Tabela 5: Participação eletrônica em chats, votação etc.

\begin{tabular}{l|l|l}
\hline \multicolumn{2}{l}{ Percentual (\%) } & Participar em fóruns, chats, votações, etc relacionados ao governo \\
\hline \multicolumn{2}{l}{ Total } & 10 \\
\hline \multirow{2}{*}{ Área } & Urbana & 10 \\
\cline { 2 - 3 } & Rural & 8 \\
\hline \multirow{4}{*}{ Região } & Sudeste & 10 \\
\cline { 2 - 3 } & Nordeste & 11 \\
\cline { 2 - 3 } & Sul & 10 \\
\cline { 2 - 3 } & Norte & 9 \\
\cline { 2 - 3 } & Centro-Oeste & 12 \\
\hline \multirow{2}{*}{$\begin{array}{c}\text { Renda } \\
\text { familiar }\end{array}$} & Até 1 SM & 6 \\
\cline { 2 - 3 } & Mais de 1 SM até 3 SM & 10 \\
\cline { 2 - 3 } & Mais de 3 SM & 11 \\
\hline
\end{tabular}

Nota. Base: 6680 pessoas com 16 anos ou mais que utilizaram governo eletrônico nos últimos 12 meses em relação ao momento da entrevista. Fonte: Adaptado pela autora a partir de dados do Núcleo de Informação e Coordenação do Ponto BR (2012). Pesquisa sobre o uso das tecnologias de informação e comunicação no Brasil: TIC Domicílios e TIC Empresas 2011. (p. 483). SP: CGI.

Pinho (2008) sintetizou tais questões sobre a falta de participação digital e avançou na discussão ao propor o uso de um conceito ampliado de governo eletrônico, que não se limita ao uso das TICs para provisão de serviços, incorporando a variável política na sua definição.

A forma ampliada de governo eletrônico não nega as conquistas da forma restrita, mas passa a considerar duas frentes interconectadas: por um lado, um Estado mais responsivo, aberto à participação da sociedade e transparente e, por outro, considera um papel protagonista da sociedade civil, atribuindo a essas possibilidades, por intermédio dos cidadãos e/ou de movimentos sociais, de checar, aferir, controlar o governo (de maneira mais geral, o próprio Estado) e, ainda, de assumir um papel propositivo. (PINHO, 2008, p.477)

Será que o cidadão sabe utilizar-se desse exercício de política (e de poder)? O cidadão é o habitante da cidade, mas no olhar político, cidadão é o habitante de um Estado livre, com direitos 
civis e políticos. É o ser cidadão, apoiado num conjunto de direitos e deveres que definem a cidadania em suas várias facetas, entre elas a cidadania digital, que segundo Anjos e Ezequiel (2006) é realizada prioritariamente através das tecnologias de governo eletrônico, já que dos elementos constituintes do governo eletrônico, tal discussão tem impacto direto no G2C (Government to Citizens), nas relações externas que envolvem a interação com os indivíduoscidadãos.

O conceito de cidadania envolve a participação cidadã, com o engajamento da sociedade civil, como um componente importante da esfera democrática. Participação que contribui para a deliberação e tomada de decisões políticas através de mecanismos de feedback. Segundo Rose e Sanford (2007), a cidadania digital da mesma forma apoia-se na participação digital (eparticipação), como uma evolução de um comportamento social que é facilitado por meio das TICs e outras tecnologias de apoio, mas que possui como importante fator limitante para a efetiva prática da e-participação, a acessibilidade, ou a questão da desigualdade de acesso às tecnologias. Para Lemos (2006), exercer o papel de cidadão digital é viver num contexto que permita isso, tal contexto são as cidades digitais.

Com o objetivo de possibilitar esse caminho, os governos têm trabalhado no projeto de criar cidades digitais para ampliar a inclusão digital. A criação dessas cidades digitais abre a possibilidade de ampliar a transferência para o mundo virtual das relações que ocorrem no mundo real e a posssbilidade do cidadão, usuário de governo eletrônico, transformar-se cada vez mais num cidadão digital.

Em virtude desse cenário, em 19 de agosto de 2011 o Ministério das Comunicações através da portaria 376 instituiu o Projeto de Implantação e Manutenção das Cidades Digitais, como parte do programa de Governo Eletrônico brasileiro, para estruturação das cidades digitais brasileiras em função da necessidade de garantir a oferta dos serviços de telecomunicações aos cidadãos e aos governantes municipais, dentro dos mais atuais padrões de modernidade e economicidade, visando à inclusão social, participação digital da população e a melhoria da gestão administrativa na prestação de serviços públicos de saúde, educação e segurança. Como parte inicial do Projeto do Minc (2011) e antes desse edital, o Ministério das Comunicações já testou tecnologias de conexão em diversas cidades do país, nos chamados projetos-piloto, tais como nas cidades de Tiradentes (MG) ou Garanhuns e Caetés (PE).

O Ministério das Comunicações neste edital pretende implantar 163 (cento e sessenta e três) cidades digitais, através desse projeto, que tem o objetivo de:

1. constituir redes digitais locais de comunicação nos municípios brasileiros;

2. promover a produção e oferta de conteúdos e serviços digitais;

3. facilitar a apropriação de tecnologias da informação e da comunicação pela gestão pública local e pela população, de maneira coordenada e integrada entre esferas dos poderes públicos e da sociedade. 
E, em última instância, garantir a possibilidade de participação nos processos de governo eletrônico e na elaboração e aplicação de políticas públicas.

O que se percebe, no entanto, é o aparecimento de uma crise de legitimidade, que acontece, segundo Gomes (2005), em grande parte, pelo distanciamento do cidadão da esfera de decisões políticas, a esfera política encontra-se distante do cotidiano do cidadão, ainda que seja ele o responsável pela eleição dos seus representantes políticos. Este novo contexto demanda a efetiva prática da cidadania digital que necessita de uma sinergia entre alguns elementos como as cidades digitais e governança eletrônica ativa num contexto de interação e e-participação que tem se ampliado vertiginosamente e pode, nos casos de maior efetividade, vir a impactar o desenvolvimento humano das cidades onde ocorrem essas iniciativas.

A finalidade da e-participação é aumentar a capacidade dos cidadãos de transformar a relação com o governo nos serviços digitais, melhorando sua eficiência, bem como participar do processo político. Promover a cidadania digital, para Saebo et al. (2008), não se resume a garantir acesso aos serviços eletrônicos (gratuitos ou pagos) oferecidos via e-gov, mas também reconhecer a particularidade de cada cidadão diretamente ligada à condição social do indivíduo e sua capacidade de expressar sua posição nas questões ligadas à gestão pública.

O projeto das Cidades Digitais caracteriza-se como uma inovação e como tal demanda um estudo e planejamento de todos os seus projetos e condicionantes para que, de fato, venha a ser adotado e venha a representar um marco não só para a inclusão digital, como para a possibilidade do exercício da cidadania digital brasileira.

\section{Difusão da Inovação}

No cenário tecnológico brasileiro, as cidades digitais são um projeto de inovação, a partir da introdução e disponibilização de tecnologias e processos que visam permitir não só a ampliação da inclusão digital com acesso a internet gratuito, bem como a abertura do caminho para a utilização de serviços de governo eletrônico através desses acessos e com isso a possibilidade do exercício da cidadania digital.

Para Tidd, Bessant e Pavitt (2005) falar em inovação é essencialmente falar em mudança. As mudanças tecnológicas são usualmente diferenciadas por seu grau de inovação e pela extensão das mudanças em relação ao que havia antes. [...] classificada [...] segundo seus impactos como: [...] inovações incrementais [...] abrangem melhorias feitas no design [...] aperfeiçoamentos em layout e processos [...] e ocorrem de forma contínua [...]. (TIGRE, 2006, pp. 73-74),

como no caso do projeto de inovação das Cidades Digitais que visa provocar melhoramentos e modificações cotidianas na inserção digital da população em geral, principalmente para aqueles que atualmente dispõem de menor acesso.

As inovações possuem características, segundo Rogers (2003), inerentes a sua aplicabilidade e influência na sociedade, tais como: vantagem relativa (grau de percepção do quanto uma inovação é superior às ideias que ela sucede), compatibilidade (grau de consistência 
aos valores, experiências passadas e necessidades dos potenciais adotantes), complexidade (grau de dificuldade da utilização), experimentabilidade (grau de possibilidade de teste/ experimento numa base limitada), observabilidade (grau de visibilidade da inovação). Dessa forma o projeto das Cidades Digitais não basta ser considerado pelo governo como inovador, mas terá que ter vantagem de percepção relativa, ser compatível com as experiências da população, ser capaz de prover a experimentabilidade e capacitar a população para essa utilização, além de ter um elevado grau de observabilidade, para que de fato venha a ser utilizado e para os fins aos quais se destina. Para isso, é extremamente importante que haja um correto processo de difusão da inovação como forma de garantir a possibilidade de sucesso do projeto.

Os processos de inovação e difusão, entretanto, não podem ser totalmente separados, pois em muitos casos a difusão contribui para o processo de inovação. A difusão de um produto ou processo no mercado revela problemas que podem ser corrigidos em novas versões. Assim, a difusão alimenta e direciona a trajetória de inovação, revelando as necessidades cambiantes da demanda por soluções técnicas. (TIGRE, 2006, p.73)

Para Rogers e Schoemaker (1971 como citado em Tigre, 2006, p.73) a difusão pode ser definida como o processo pelo qual uma inovação é comunicada através de certos canais, através do tempo, entre os membros de um sistema social.

Difusão é um tipo especial de comunicação, no qual as mensagens são sobre novas ideias. [...] a novidade significa que algum grau de incerteza está envolvido na difusão. [...] é um tipo de mudança social definida como o processo pelo qual ocorrem alterações na estrutura e funções de um sistema social, [...] determinadas consequências, mudanças sociais ocorrem. (ROGERS, 2003, p.6)

"A dinâmica da difusão pode ser entendida como a trajetória de adoção de uma tecnologia no mercado, com foco nas características da tecnologia e nos demais elementos que condicionam seu ritmo e direção" (Tigre, 2006, p.78). No caso das Cidades Digitais essa dinâmica precisa ser cuidadosamente planejada, já que segundo Tigre (2006), o processo de difusão tecnológica é usualmente analisado a partir de quatro dimensões básicas: (a) direção ou trajetória tecnológica; (b) ritmo ou velocidade de difusão; (c) fatores condicionantes, tanto positivos quanto negativos; e (d) impactos econômicos e sociais. Esses aspectos carecem de estudos aprofundados, já que segundo Rogers (2003) a percepção de novidade da inovação bem como a incerteza associada gera um processo mais complexo de decisão, pois é um projeto que não envolve apenas a disponibilização de tecnologia, mas principalmente a capacitação para seu uso, já que o ritmo (velocidade de sua adoção pela sociedade e evolução do número de adotantes) é um dos fatores chaves para que de fato o projeto das Cidades Digitais seja efetivo.

O processo de decisão da inovação no projeto das Cidades Digitais, baseando-se em Rogers (2003), se dá quando um indivíduo ou outra unidade de decisão passa do conhecimento sobre a inovação até formar uma atitude sobre a inovação, a decisão de adotar ou rejeitar e finalmente implementar a nova ideia e confirmar a decisão, ou seja passa da avaliação da nova ideia à incorporação ou não da inovação na sua prática. Nesse processo, a etapa de difusão da inovação revela-se importante para que a inovação seja adotada, por isso é importante observar 
os quatro elementos principais da difusão da inovação descritos por Rogers (2003): inovação (ideia, prática ou objeto percebido como novidade) especificamente no caso das cidades digitais como uma inovação tecnológica composta de hardware e software, mas que envolve as pessoas para sua utilização e um grau de incerteza pela expectativa das consequências; canais de comunicação, tempo e sistema social envolvido.

Nesse processo de decisão sobre a inovação é importante estar atendo aos seis estágios envolvidos, de acordo com Rogers (2003): conhecimento (quando há o contato individual com a inovação e entendimento sobre suas funções), persuação (atitude favorável ou desfavorável à inovação a partir do envolvimento psicológico com a inovação e sofre influência dos canais de comunicação), decisão (escolha sobre adoção ou rejeição ativa ou passiva), implementação (utilização da inovação, colocação em prática, ainda com um grau de incerteza quanto às consequências da adoção) e confirmação (reforço positivo ou negativo em relação a inovação, nesse caso muitas vezes podendo haver a reinvenção). O processo envolverá os adotantes iniciais que normalmente têm características similares aos inovadores por terem um nível educacional e socioeconômico superior, por isso são importantes como aliados no processo de inovação. Para Rogers (2003), a adoção da inovação muitas vezes sofre a reinvenção com algumas alterações de suas características iniciais, já que muitas vezes há dificuldade de entendimento quanto ao seu propósito ou utilização, não levando a sua finalidade de utilização como pode acontecer no caso das cidades digitais, longe de atingir sua característica da abertura para a prática da cidadania digital.

Um das dificuldades encontradas para o projeto refere-se aos condicionantes técnicos, já que a difusão é condicionada pelo grau em que uma inovação é percebida como difícil de ser entendida e usada. "Quanto mais complexa a tecnologia, maior será a necessidade de suporte técnico para a solução de problemas" (TIGRE, 2006, p.82). Para a parcela da população que não tem acesso ao computador ou a internet, percentuais observados nas tabelas 1 e 2, dispor apenas de tecnologia não levará efetivamente à utilização da inovação.

Para Andrade (2006), mais do que espectadores ou consumidores de inovações ou equipamentos novos, os diversos atores da sociedade civil constituem elementos-chave para a viabilidade ou não de determinados projetos tecnológicos, já que a sua real utilização e principalmente a utilização para a qual sua finalidade foi estabelecida dependerá da decisão desses atores que passam pelo processo de decisão da inovação, mas que são condicionados por fatores econômicos, sociais e culturais. Por isso faz-se necessário administrar melhor a atividade inovativa para criar ambientes de circulação de informação mais abertos e eficientes nessas cidades. Diferente da lógica comum da invenção, a inovação não se baseia apenas na busca de novas propriedades técnicas ou novos produtos. Sua ênfase recai sobre a compatibilização entre o avanço tecnológico e as instituições sociais existentes, ou, nos termos de Gille (1978 citado em ANDRADE 2006) entre o sistema técnico e os outros sistemas sociais.

O aproveitamento de uma determinada tecnologia e sua consequente inovação envolve a busca compartilhada de suas propriedades intrínsecas e as condições 
circunstanciais de seu aproveitamento. Segundo Latour, não se pode imputar somente ao quadro das condições sociais o sucesso ou fracasso de uma dada inovação, mas às propriedades técnicas que por sua vez se transformam mediante a mobilização e adesão de um caldo de agentes diferenciados, humanos e não-humanos, formadores de um contexto técnico e social instável. Latour denuncia veementemente o determinismo social embutido fortemente nos estudos sobre tecnologia, que seria responsável pelo estabelecimento de uma séria abstração sociológica, que desconecta as contingências sociais da operacionalização técnica. (ANDRADE, 2006, p. 159)

Segundo Giacomini et al. (2007) as questões culturais, políticas e ideológicas condicionam a forma como uma novidade é percebida. Hockenbury e Hockenbury (2003, como citado em GIACOMINI et al., 2007, p. 43) corroboram com tal significado de que a percepção acontece quando integramos, organizamos e interpretamos as informações sensoriais de forma significativa. Porém os mesmos autores alertam que as nossas experiências educacionais, culturais e de vida modelam aquilo que percebemos.

Os ambientes de inovação levam em consideração elementos advindos da
herança cultural e da criatividade peculiar de um grupo social, que
tradicionalmente não são reconhecidos como componentes de inovação. [...] De
acordo com essa corrente de pensamento, a inovação depende menos de
investimento intensivo de capital e inventividade técnica, e mais da criação de
redes de circulação de informação e conhecimento. A problemática da inovação
torna-se menos tecnológica e mais pedagógica, adquire um sentido econômico
(distributivo) e social (coesão) que transcende os ditames operacionais e
funcionais dos objetos técnicos. [...] As formas de utilização e percepção das
tecnologias digitais implicam novas formas de coesão e relacionamento
interinstitucionais. (ANDRADE, 2006, pp. 146-150)

Para Andrade (2006), só é possível compreender o fracasso ou êxito de um projeto tecnológico mediante o exame tanto das condições institucionais e coletivas de uma determinada conjuntura, como de fatores que são erroneamente denominados técnicos, pois envolvem processos de recrutamento de disponibilizações sociais. Nesse caso, os aspectos técnicos são indissociáveis do rol de preferências culturais e políticas que os agentes manifestam, principalmente no caso de um projeto, como o das Cidades Digitais, que envolve camadas menos favorecidas da população.

Será importante o papel dos canais de comunicação, que, de acordo com Rogers (2003) são ferramentas que auxiliam no processo de difusão da inovação, podendo ser utilizados canais de mídia de massa (potencializam a divulgação mais rapidamente, mas que muitas vezes são influência em menor grau por isso tem maior valor nos estágios de conhecimento), utilizando ferramentas de mídia para dissipar as mensagens; como canais interpessoais (comunicação face a face) que facilitam a troca de informação e ampliam o grau de persuasão, sendo mais importante nos estágios de persuasão e decisão. Opiniões de líderes são, também, uma grande fonte de influência em atitudes de outros indivíduos, conforme Rogers (2003) denominou, são agentes de mudança que influenciam decisões e no caso desse projeto atores extremamente importantes, que devem ser considerados no processo de difusão da inovação. Já que, "uma pessoa pode ser estimulada com uma nova tecnologia ou ideias inovadoras, mas que apenas serão inovações se essa pessoa, dentro de seu universo cognitivo, atribuir significado de 
inovação, podendo a partir daí aceitar ou rejeitar sua apropriação" (GIACOMINI et al., 2007, p. 43).

Os analistas que, com base em grupos de interesses, explicam como se dissemina uma ideia, como uma teoria é aceita ou uma máquina é rejeitada não têm consciência de que os mesmos grupos, os mesmos interesses que eles veem como causas em suas explicações são consequência da extração e da purificação artificiais de um punhado de vínculos que provêm dessas ideias, teorias, ou máquinas. (LATOUR, 2000 como citado em ANDRADE, 2006, p. 159)

São esses vínculos que permitirão a aceitação ou rejeição da inovação e por isso a atividade da difusão torna-se tão importante no processo.

Segundo Jaeger e Bertot (2010) muitos cidadãos consideram o governo eletrônico autoritário, sem efetivos canais de comunicação e participação do cidadão dificultando a prática da democracia digital. Um novo modelo de governo eletrônico deve ser operado no espaço virtual das cidades que se constituem em economias digitais, permitindo a interação numa sociedade do conhecimento, podendo utilizar de forma intensiva as redes e mídias sociais como elementos integradores desse processo de democracia e, um dos instrumentos, é o projeto das Cidades Digitais, que pode permitir essa abertura. O que muitas vezes se percebe, no entanto, é uma atividade desproporcional onde o Estado aparece utilizando muita tecnologia e pouca democracia, o que compromete a vivência da cidadania digital.

Para Pinho (2008), a abertura por parte dos governos para a transparência e participação societal depende de todo um processo histórico e do balanço de forças políticas existentes na sociedade. Não ficando restrito, entretanto, a uma questão de tecnologia, mas também à vontade política e projetos inovadores apoiados por um conjunto de fatores onde a difusão da inovação assume importante papel.

\section{CONSIDERAÇÕES FINAIS}

O resgate de suas elaborações para a reflexão sobre a inovação e o avanço tecnológico teria duas consequências principais: em primeiro lugar, a inovação não deve significar desenvolvimento, em suas fórmulas lineares e evolutivas, mas desestabilização de relações, que irão se reordenar a partir do estabelecimento de novas institucionalidades sociais. [...] o determinismo tecnológico não pode ser substituído pelo determinismo sociológico. (ANDRADE, 2006, p. 162).

O conceito de governo eletrônico, para Chen et al. (2009), vai além da atividade de fazer uso das TICs pelas instituições governamentais para melhorar a sua eficiência operacional e eficácia na satisfação das necessidades dos cidadãos e prestação de serviços. Apesar da difusão mundial de iniciativas de governo eletrônico, uma transição adequada para a prática da democracia e conquista da cidadania digital pode levar tempo em função não só de razões tecnológicas, bem como de organização, vocação e vontade política.

Cabe destacar que a implantação do efetivo governo eletrônico enfrenta desafios segundo Budhiraja (2003); Araújo e Gomes (2004) como questões organizacionais, jurídicas e, principalmente, culturais, presentes e divergentes em cada cidade digital. Além disso, o fator 
político que envolve a vontade política dos governantes destaca-se como fator fundamental para que de fato um projeto como esse possa ser realizado com plenitude para que não seja apenas uma inovação tecnológica sem nenhum alcance social. É necessário mudar a mentalidade dos governantes para que se promova mudança na sua estrutura e cultura visando este nível de integração e a possibilidade efetiva da prática da cidadania. O que pode ser consequência de projetos como o das Cidades Digitais: uma inovação como caminho para a prática da cidadania digital.

Para isso, percebe-se a necessidade de um adequado projeto de difusão dessa inovação, entendendo a realidade de cada comunidade como necessária para elaboração desse projeto a partir da análise de todos os fatores e particularidades envolvidos. Um projeto de difusão como importante elemento catalisador desse processo, que leve a não só disponibilizar tecnologia pelo "ter tecnologia", mas para criar de fato a possibilidade do cidadão tornar-se um cidadão digital que possa participar da vida cultural, social e política da sociedade.

A internet como local de interação pública através da participação digital possui as mesmas exigências de funcionamento dos espaços públicos presenciais, para isso é preciso [...] considerar fatores relativos ao arranjo social e político que são anteriores ao advento dos media digitais, tais como a disposição dos agentes e instituições em compartilhar poder e o estímulo dos cidadãos em acreditar e utilizar as ferramentas. (MARQUES, 2008 p. 248)

O estudo desse tema encontra-se em fase inicial por tratar-se de um novo projeto do Governo Federal. Estudos complementares ou extensivos ao tema poderiam verificar se de fato as cidades escolhidas e que tiveram seu arcabouço digital implementado ampliaram a participação do cidadão através de processos de governo eletrônico e se de alguma forma permitiram a participação cidadã nos seus processos políticos.

Os impactos da difusão podem ser analisados sob diferentes enfoques, entre eles o social, quando envolvem inovações, ainda que tecnológicas, mas que tem relação direta com a sociedade e podem gerar consequências desejáveis ou indesejáveis e, também, o enfoque político onde se questiona a vontade da esfera política de permitir a participação cidadã no seu processo de elaboração, execução e acompanhamento de políticas públicas.

Um processo de difusão de uma inovação que tem associada um risco social mas que pode ser materializado na construção de uma sociedade mais democrática e sustentável, como no caso do projeto das Cidades Digitais que, se bem elaborado, implantado e difundido pode levar a ampliação da cidadania digital na construção da democracia digital no Brasil.

\section{REFERÊNCIAS}

ANJOS, G. M. A. A.; EZEQUIEL, V. C.. Cidadania virtual: o espetáculo do governo eletrônico. São Paulo. Estudos de Sociologia, v.16, n.30, p.59-76, 2011.

ANDRADE, T. N.. Aspectos sociais e tecnológicos das atividades de inovação. Lua Nova, São Paulo, v.66, p.139-166, 2006. 
ARAÚJO, W. F. G.; GOMES, M. P. S.. Governança eletrônica na América Latina: podemos esperar uma democracia eletrônica?. In: FÓRUM IUOERJ/UFMG: democracia e desenvolvimento na América Latina. Anais. Rio de Janeiro, 2004.

AZIZAN, N.; SMITH, R.; COOPER, V.. Critical success factors for knowledge transfer via government websites. Journal of E-Government Studies and Best Practices, 2011

BUDHIRAJA, R.. Eletronic governance: a key issue in the $21^{\text {st }}$ century. 2003.

CASTELLS, M.. A sociedade em rede. São Paulo: Paz e Terra, 1999.

CASTELLS, M.. A galáxia da internet: reflexões sobre a internet, os negócios e a sociedade. Rio de Janeiro: Jorge Zahar, 2003.

CHEN, J.; YEN, D. C.; CHEN, K.. The acceptance and diffusion of the innovative smart phone use: A case study of a delivery service company in logistics. Information and Management, v.46, p.241-248, 2009.

CEGE. Comitê Executivo do Governo Eletrônico. Diretrizes das políticas de Governo Eletrônico no Brasil de 2010. Brasília: CEGE, 2010.

DOSI, G.. Technological difusion: the theory and some methodological suggestions for the brazilian case. Brasília: IPEA, 1985.

FERNANDES, C. C. C.. Maturidade do governo eletrônico: análise de experiências estaduais. Projeto de Pesquisa (Doutorado Gestão Estratégica da Informação) - Escola de Administração de Empresas de São Paulo da FGV, São Paulo, 2006.

FREEMAN, C.; SOETE , L.. A economia da inovação industrial. Campinas: EdUNICAMP, 2008.

GIACOMINI, F. O. G.; GOULART, E.; CAPRINO, M.. Difusão de inovações: apreciação crítica dos estudos. Revista FAMECOS, Porto Alegre, n.33, 2007.

GOMES, W.. A democracia digital e o problema da participação civil na decisão política. Revista Fronteiras, v.2, n.3, p.214-222, 2005.

JAEGER, P. T.; BERTOT, J. C.. Designing, implementing, and evaluating user-centered and citizen-centered e-government. International Journal of Electronic Government Research, v.6, n.2, p.1-17, 2010.

JARDIM, J. M.. Governo eletrônico no Brasil: o portal rede governo. Arquivística.NET, v.3, n.1, p. 28-37, 2007.

KIM, L.; NELSON, R.. Tecnologia, aprendizado e inovação. Campinas: EdUNICAMP, 2005

KIM, L.. Da imitação à inovação. Campinas: EdUNICAMP, 2005.

LEMOS, A.. O que é Cidade Digital?. 2006. Disponível:

http://www.guiadascidadesdigitais.com.br/site/pagina/o-que-cidade-digital . Acesso: 25 Set 2011.

MARQUES, F. P. J.. Participação política e internet: meios e oportunidades digitais de participação civil na democracia contemporânea. Tese (Doutorado em Comunicação) - Faculdade de Comunicação da Universidade Federal da Bahia, Salvador, 2008.

MIMICOPOULOS, M. G.; KYJ, L.; SORMANI, N.; BERTUCCI, G.; QIAN, H.. Public governance indicators: a literature review. New York: ST/ESA/PAD/SER.E/100, United Nations, 2007.

MINISTÉRIO DAS COMUNICAÇÕES. Projeto de implantação e manutenção das cidades digitais: Portaria 376 de 19/08/2011. Brasília: D.O.U., 2011.

NELSON, R.. The sources of economic growth. Cambridge: Harvard UniversityPress, 1996.

NIC. Núcleo de Informação e Coordenação do Ponto BR. Pesquisa sobre o uso das tecnologias de informação e comunicação no Brasil: TIC domicílios e TIC empresas 2011. São Paulo: Comitê Gestor da Internet no Brasil, 2012. 
OECD. Manual de Oslo: diretrizes para coleta e interpretação de dados sobre inovação. Brasília: FINEP, 1997.

PINHO, J. A. G.. Investigando portais de governo eletrônico no Brasil: muita tecnologia, pouco democracia. Revista de Administração Pública, v.42, n.3, p.471-93,

2008.

RODRIGUEZ, C.; DINIZ, E., FERRER, F.. Influência governamental e estratégias institucionais na difusão de inovações em economias emergentes. RAE, v.47, n.1, 2007.

ROGERS, E.. Difusion of innovations. New York: The free Press, 2003.

ROSE, J.; SANFORD, C.. Mapping eParticipation research: four central challenges. Communications of the Association for Information Systems, v.20, 2007.

SAEBO, O.; ROSE, J.; SKIFTENES, F.. The shape of eParticipation: characterizing an emerging research area. Government Information Quarterly, v.25, p.400-428, 2008.

SANTOS, E. M.. Desenvolvimento e implementação de padrões de interoperabilidade em governo eletrônico no Brasil. Tese (Doutorado) - Universidade de São Paulo, São Paulo, 2008.

SANTOS, E. M.. Implementing interoperability standards for electronic government: an exploratory case study of the E-PING brazilian framework. International Journal of Electronic Government Research, v.4, n.3, 2008b.

SAGHEB-TEHRANI, M.. A model of successful factors towards e-government implementation. Eletronic Government Journal, v.7, n.1, p.60-74; 2010.

SUZIGAN, W.; ALBUQUERQUE, E.; CARIO, S.. Em busca da inovação: interação universidade-empresa no Brasil. Belo Horizonte: Autentica, 2011.

TIDD, J.; BESSANT, J.; PAVITT, K.. Managging innovation: integrating technological, market and organizacional change. 3 ed. John Wiley \& Sons, 2005.

TIGRE, P.. Gestão da inovação: a economia da tecnologia no Brasil. Rio de Janeiro: Campus, 2006. 